http://jmscr.igmpublication.org/home/ ISSN (e)-2347-176x ISSN (p) 2455-0450

crossref DOI: https://dx.doi.org/10.18535/jmscr/v8i12.12

\title{
A Study on Correlation of ECG Findings with Angiographic Presentation among Acute Myocardial Infarction Patients in a Tertiary Care Hospital
}

\author{
Authors \\ Dr Modugula Bhava Pragna ${ }^{1}$, Dr S.Sreenivas ${ }^{2}$, Dr G.Sucharitha ${ }^{3}$ \\ ${ }^{1}$ Post graduate, Department of General Medicine, Andhra Medical College, Visakhapatnam \\ ${ }^{2}$ Professor and Head of the Department, Department of General Medicine, \\ ${ }^{3}$ Post Graduate, Department of General Medicine
}

\section{Introduction}

- CVD is responsible for about 30\% of all deaths worldwide each year. ${ }^{[9]}$ Nearly, $80 \%$ of these deaths occur in developing countries. Indeed, CVD is the leading cause of mortality in almost every region of the world.

- The electrocardiogram (ECG) remains a crucial tool in the identification and management of AMI. Acute risk stratification in AMI is still based on simple clinical parameters; laboratory markers and 12-lead ECG. $^{[4]}$

- The ECG has been a preliminary screening and one of the most useful diagnostic investigations in AMI. ${ }^{[5]}$

- Coronary angiography is currently the gold standard to evaluate AMI. It defines the coronary anatomy and determines the extent of epicardial coronary artery and coronary artery bypass graft disease.

- Various ECG presentations in relation with their angiographic finding will be investigated under this study. If correlation between ECG features and angiographic findings is found, a faster and less invasive method can be used to identify diseased vessel, therefore timely intervention can be implemented to lower its mortality rate.
- A detailed analysis of patterns of ST-segment elevation may influence decisions regarding the perfusion therapy. The early and accurate identification of the infarct-related artery can help predict the area of myocardium at risk and guide decisions regarding the urgency of revascularization. ${ }^{[1]}$

\section{Aims and Objectives}

1. To study the electrocardiographic and angiographic correlation in localizing the culprit vessel in acute ST segment elevation myocardial infarction.

2. To analyse established individual electrographic parameters for their sensitivity, specificity, positive predictive value, negative predictive value in predicting the culprit vessel in comparison with angiographic results.

\section{Materials and Methods}

Study Centre: King George Hospital, Andhra Medical College, Visakhapatnam.

Ethical Committee Approval: Obtained.

Study Duration: Six months. (August 2019January 2020)

Study Design: Hospital-based, cross-sectional, observational study 
Sample Size: 50 cases

- Patients who presented with typical chest pain (>30 $\mathrm{min}$ ) to the emergency department were taken ECG.

- The diagnosis of acute ST elevation myocardial infarction was made according to the following criteria:

1. Anterior wall MI: ST segment elevation by $2 \mathrm{~mm}$ or more in two or more anatomically consequent precordial leads.

2. Inferior wall MI: ST segment elevation by $1 \mathrm{~mm}$ or more in two or more anatomically consequent inferior leads.
- Patients who had the above ECG criteria and raised Troponin- $T$ were admitted in cardiology ICU and treatment is given.

- A total of 50 patients were taken into study.

- Angiogram was done within 7 days of admission

- Electrocardiographic changes in specified individual lead and the established ECG criteria for identifying the culprit artery and localizing the level of lesion were compared with angiographic localisation which is considered as gold standard.

INCLUSION CRITERIA
1. Patient who presented with acute ST segment
elevation myocardial infarction..
2. Patient who have undergone coronary angiography

\section{Statistical Analysis}

For each individual ECG criteria based on their distribution in various angiographic localisation site sensitivity, specificity, positive predictive value, negative predictive value were calculated and the $p$ value was obtained using Fisher's exact test. Statistical analysis was done using SPSS Version 20. The following observations were made.

\section{EXCLUSION CRITERIA}

1. Causes of ST segment elevation, other than myocardial infarction.

2. Left bundle branch block (LBBB).

3. Baseline ECG abnormalities other than LBBB (eg, paced rhythm, LV hypertrophy, Brugada syndrome).

4. Previous myocardial infarction

\section{Results}

The commonest risk factor was diabetes $(43.9 \%)$ followed by hypertension $(21.5 \%)$, positive family history (9.1\%), previous CAD (7.7\%), dyslipidemia (5.3\%) and asthma/COPD (2.3\%)

\section{AGE AND SEX DISTRIBUTION}

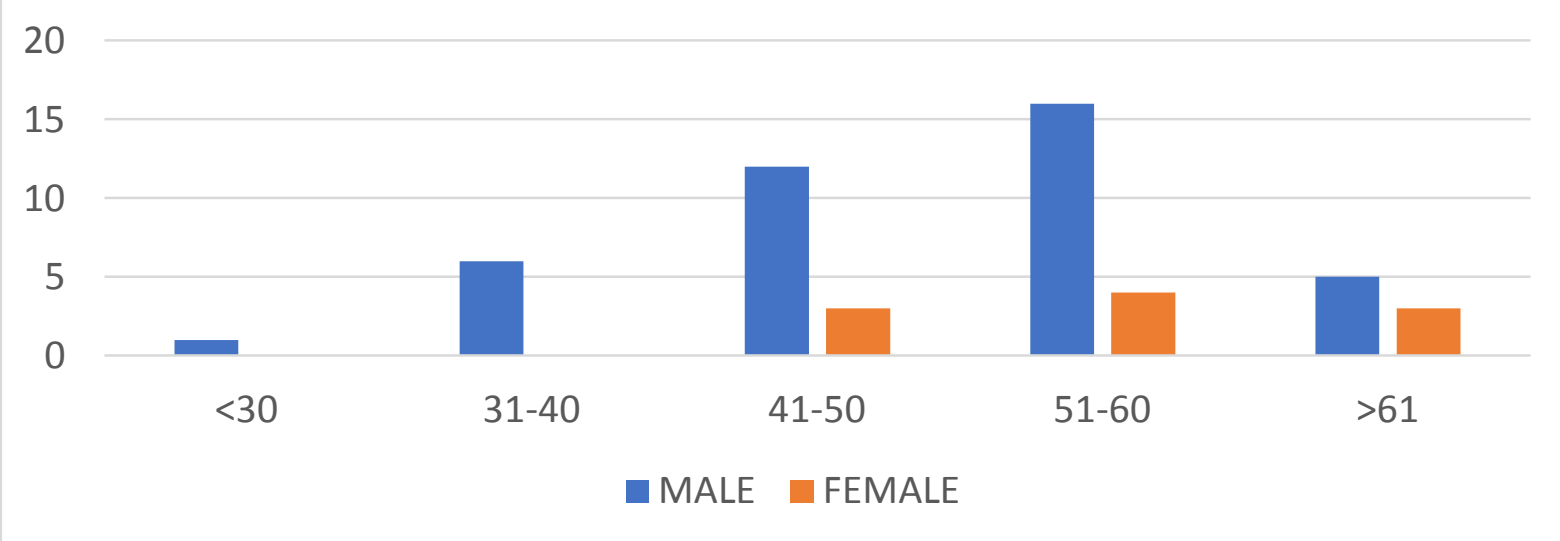


- Out of 50 patients with ST segment elevation 35 patients, i.e $70 \%$ had AWMI and $15(30 \%)$ had Inferior Wall Myocardial Infarction.
- Out of 50 patients 38(76\%) were thrombolysed, 12 (24\%)were not thrombolysed.

\section{ECG LOCALISATION}

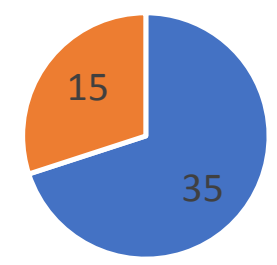

- AWMI - IWMI

\begin{tabular}{|l|c|}
\hline TREATMENT & NO.OF PATIENTS(\%) \\
\hline THROMBOLYSIS & $38(76 \%)$ \\
\hline $\begin{array}{l}\text { NOT } \\
\text { THROMBOLYSED }\end{array}$ & $12(24 \%)$ \\
\hline TOTAL & 50 \\
\hline
\end{tabular}

\begin{tabular}{|l|c|}
\hline LOCALISATION WITH ECG & NO.OF PATIENTS(\%) \\
\hline Proximal LAD & $26(52 \%)$ \\
\hline Distal LAD & $5(10 \%)$ \\
\hline LCX & $5(10 \%)$ \\
\hline Proximal RCA & $7(14 \%)$ \\
\hline Distal RCA & $7(14 \%)$ \\
\hline Total & 50 \\
\hline
\end{tabular}

\section{NUMBER OF PATIENTS}

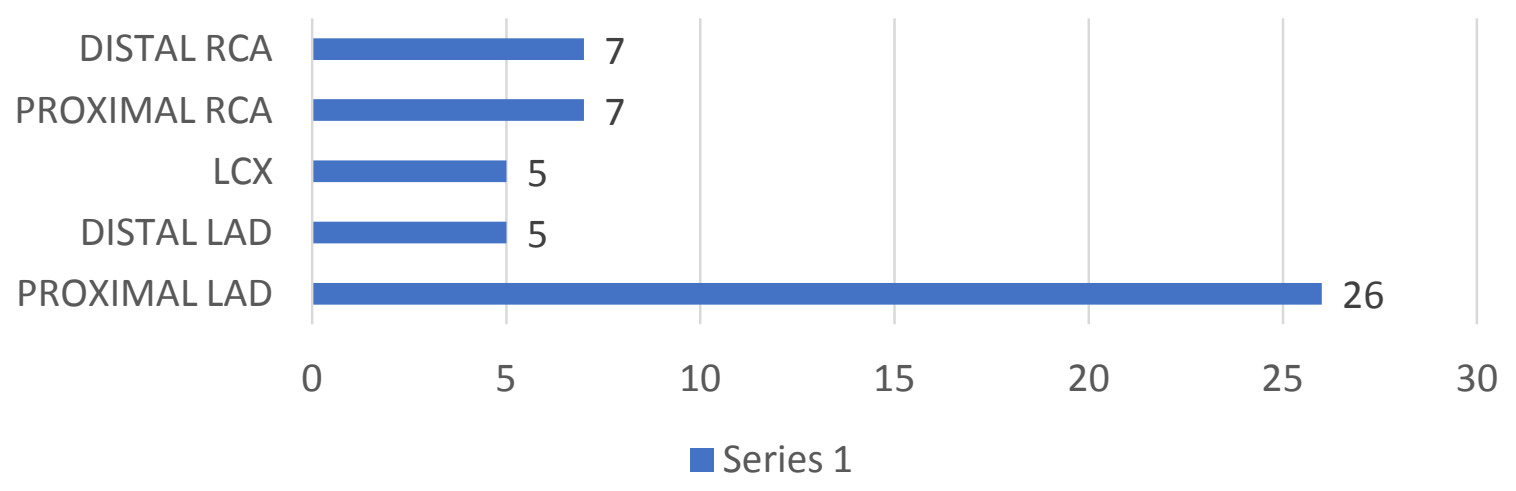




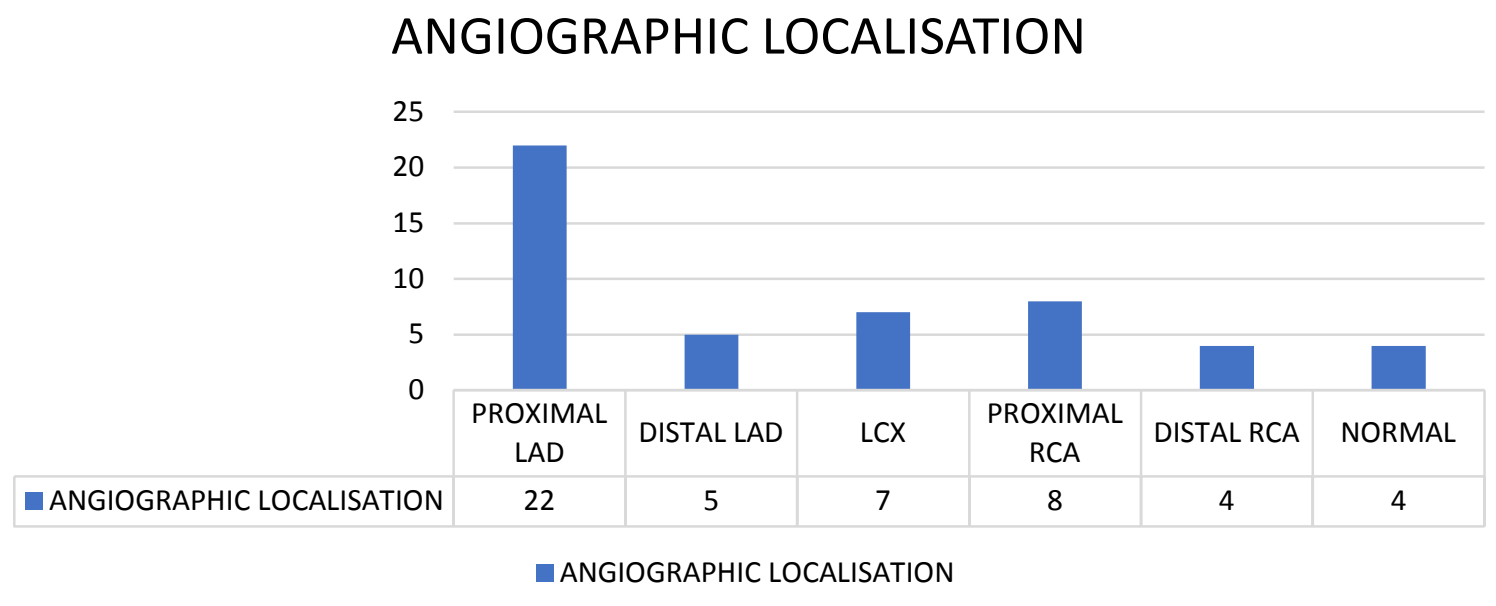

\begin{tabular}{|c|c|c|c|c|c|c|c|}
\hline $\begin{array}{l}\text { ECG } \\
\text { LOCALISA } \\
\text { TION }\end{array}$ & & & $\begin{array}{l}\text { ANGIOG } \\
\text { RAPHIC } \\
\text { LOCALIS } \\
\text { ATION }\end{array}$ & & & & \\
\hline & $\begin{array}{l}\text { Proxim } \\
\text { al RCA }\end{array}$ & $\begin{array}{l}\text { Distal } \\
\text { RCA }\end{array}$ & LCX & $\begin{array}{l}\text { Proximal } \\
\text { LAD }\end{array}$ & $\begin{array}{l}\text { Distal } \\
\text { LAD }\end{array}$ & $\begin{array}{l}\text { Nor } \\
\text { mal }\end{array}$ & Total \\
\hline $\begin{array}{l}\text { Proximal } \\
\text { RCA }\end{array}$ & 7 & 0 & 0 & 0 & 0 & 0 & 7 \\
\hline Distal RCA & 1 & 4 & 2 & 0 & 0 & 0 & 7 \\
\hline LCX & 0 & 0 & 5 & 0 & 0 & 0 & 5 \\
\hline $\begin{array}{l}\text { Proximal } \\
\text { LAD }\end{array}$ & 0 & 0 & 0 & 21 & 1 & 4 & 26 \\
\hline Distal LAD & 0 & 0 & 0 & 1 & 4 & 0 & 5 \\
\hline TOTAL & 8 & 4 & 7 & 22 & 5 & 4 & $\begin{array}{l}50=\text { tot } \\
\text { al }\end{array}$ \\
\hline
\end{tabular}

\begin{tabular}{|l|c|}
\hline ANGIOGRAM LOCALISATION & NUMBER(\%) \\
\hline PROXIMAL LAD & $22(44 \%)$ \\
\hline DISTAL LAD & $5(10 \%)$ \\
\hline LCX & $7(14 \%)$ \\
\hline PROXIMAL RCA & $8(16 \%)$ \\
\hline DISTAL RCA & $4(8 \%)$ \\
\hline NORMAL & $4(8 \%)$ \\
\hline
\end{tabular}




\section{ECG \& ANGIOGRAPHIC LOCALISATION}
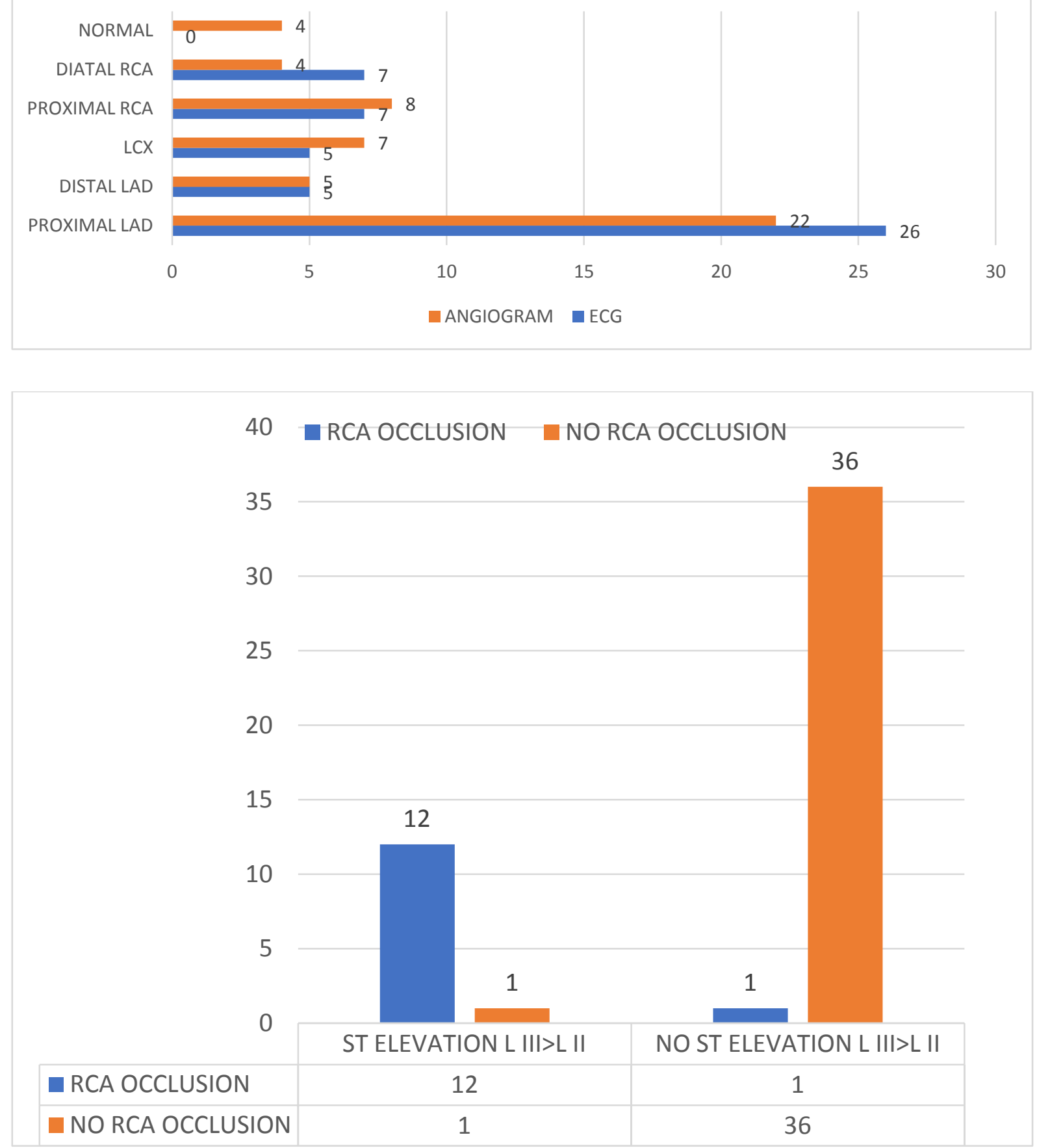

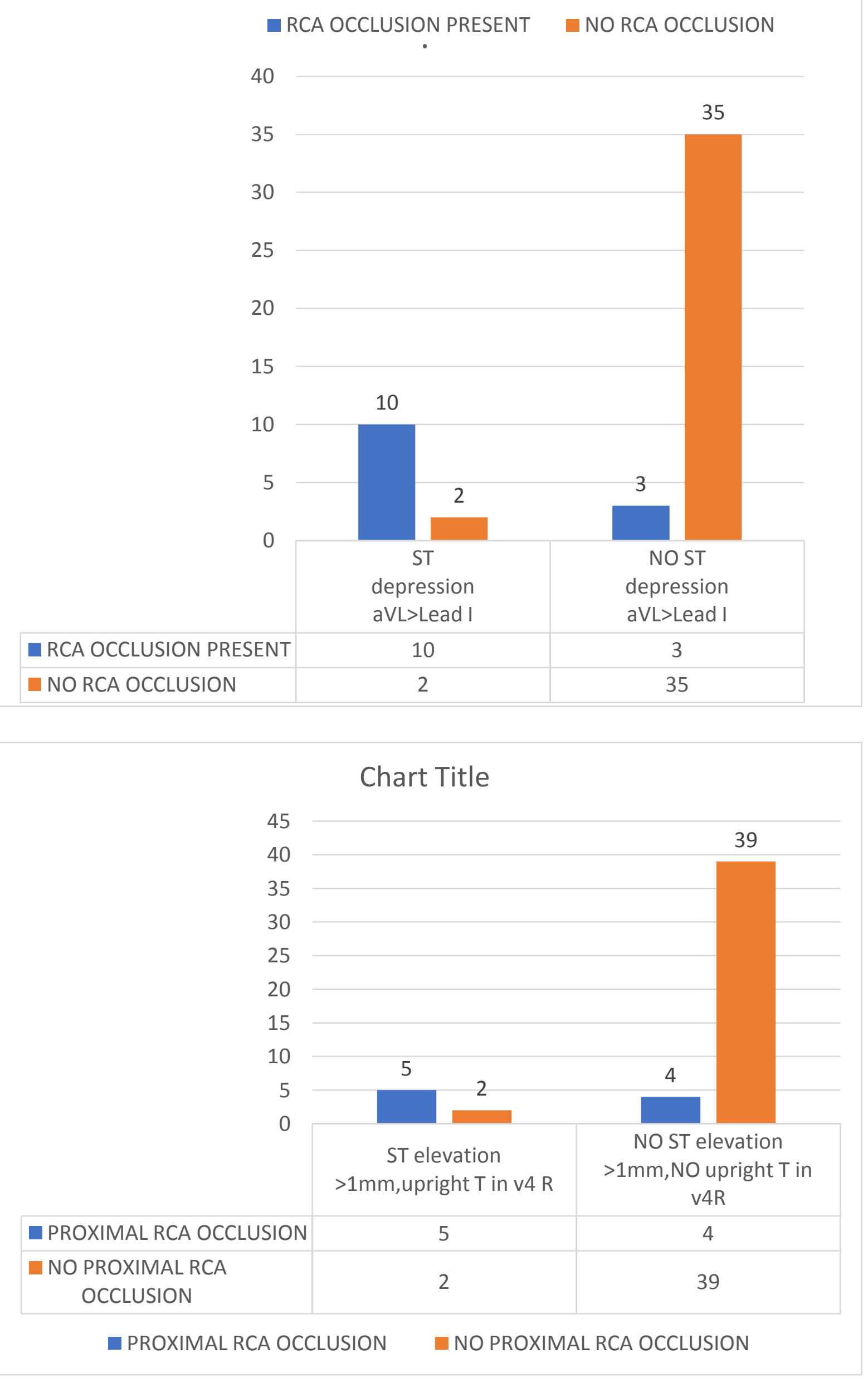


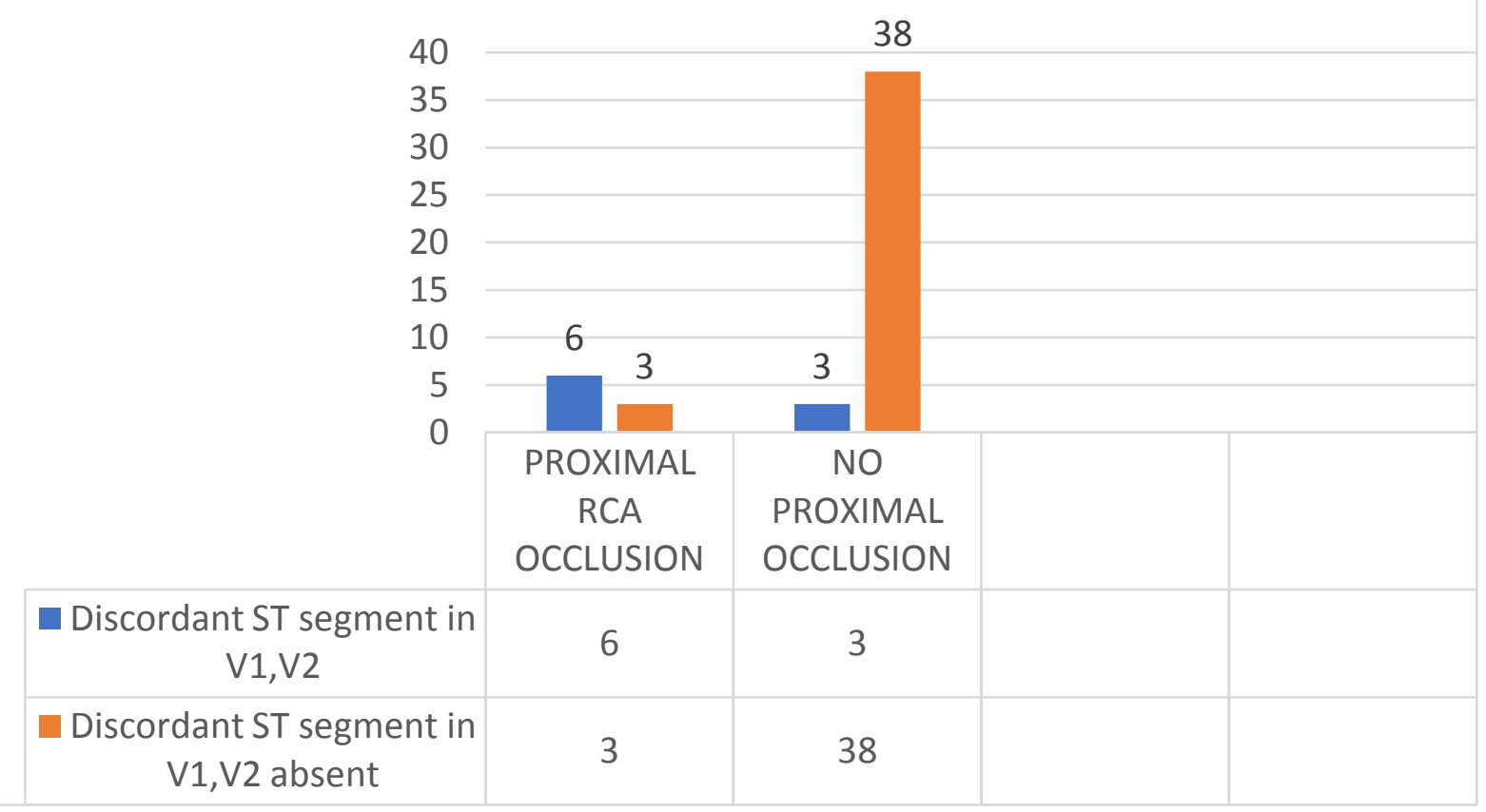

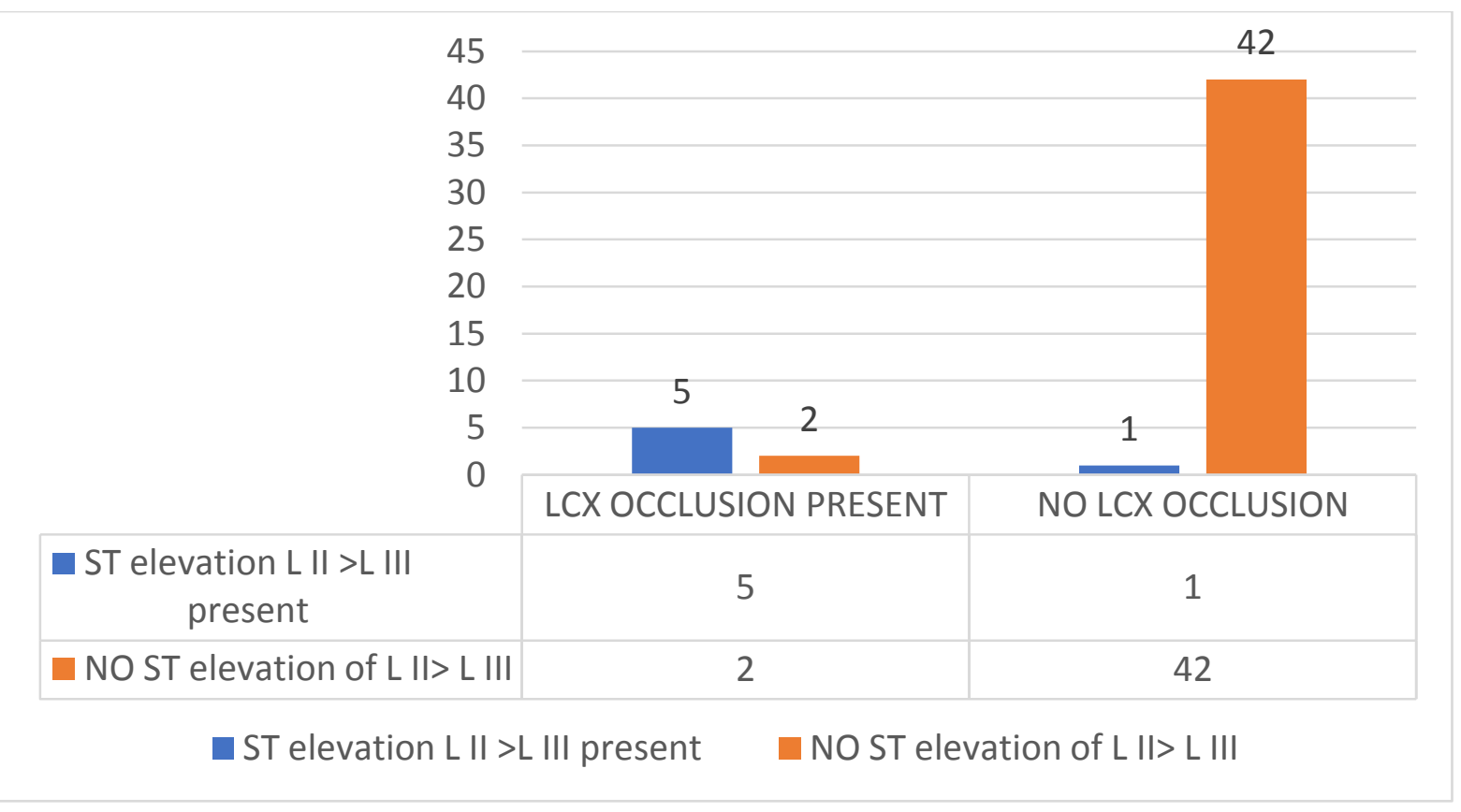



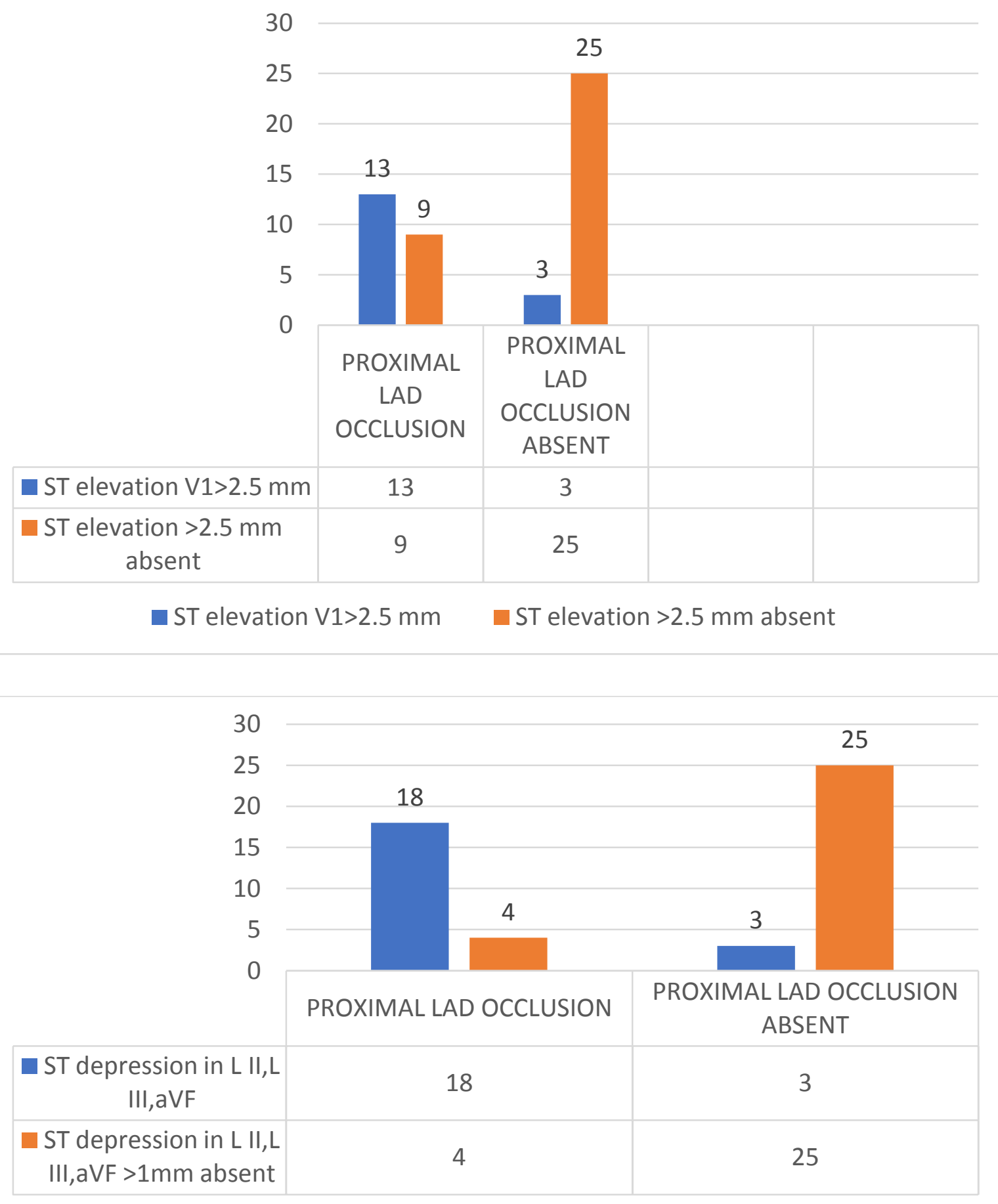

- ST depression in L II,L III,aVF $\quad$ ST depression in L II, L III,aVF >1mm absent 


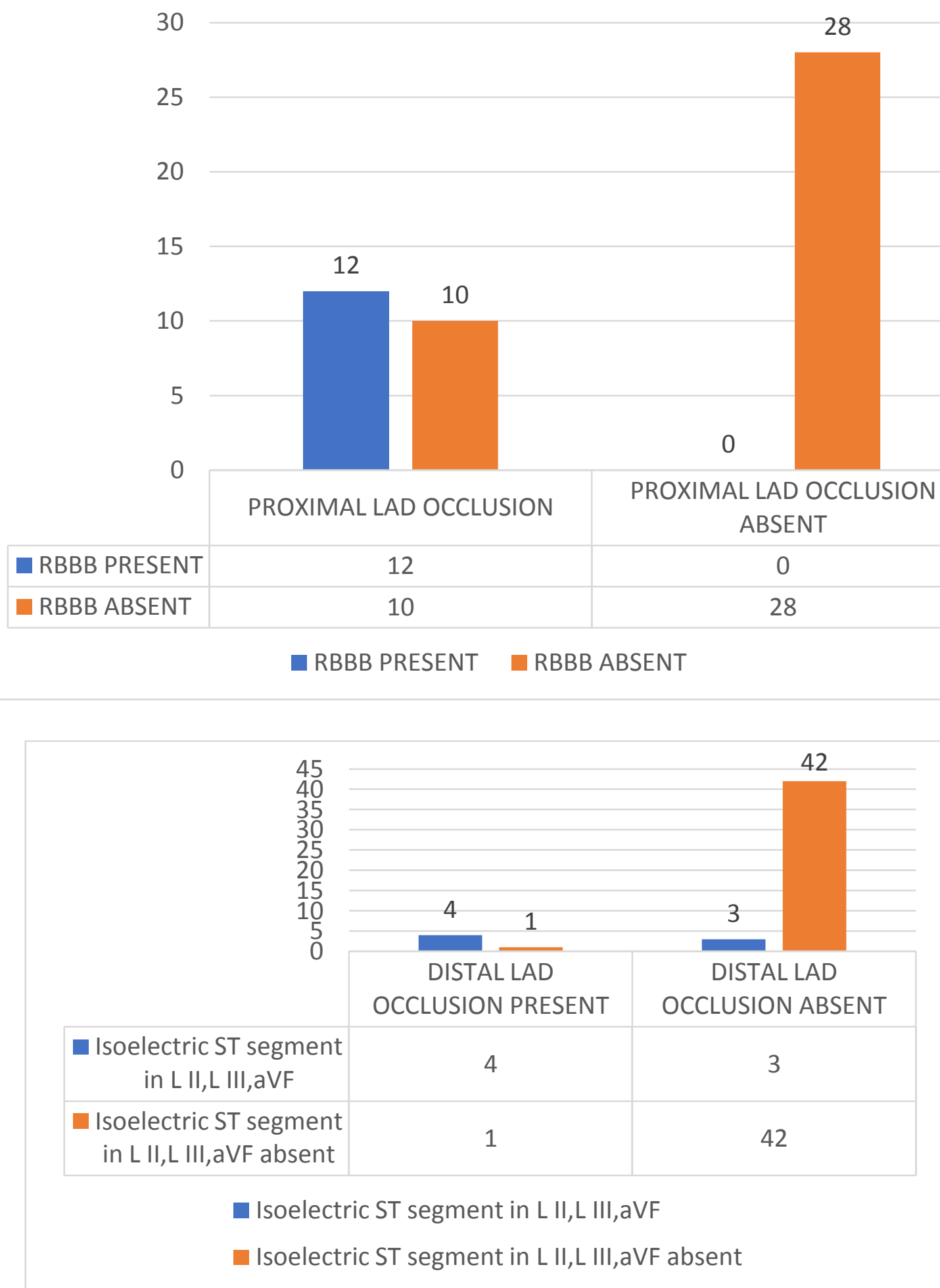




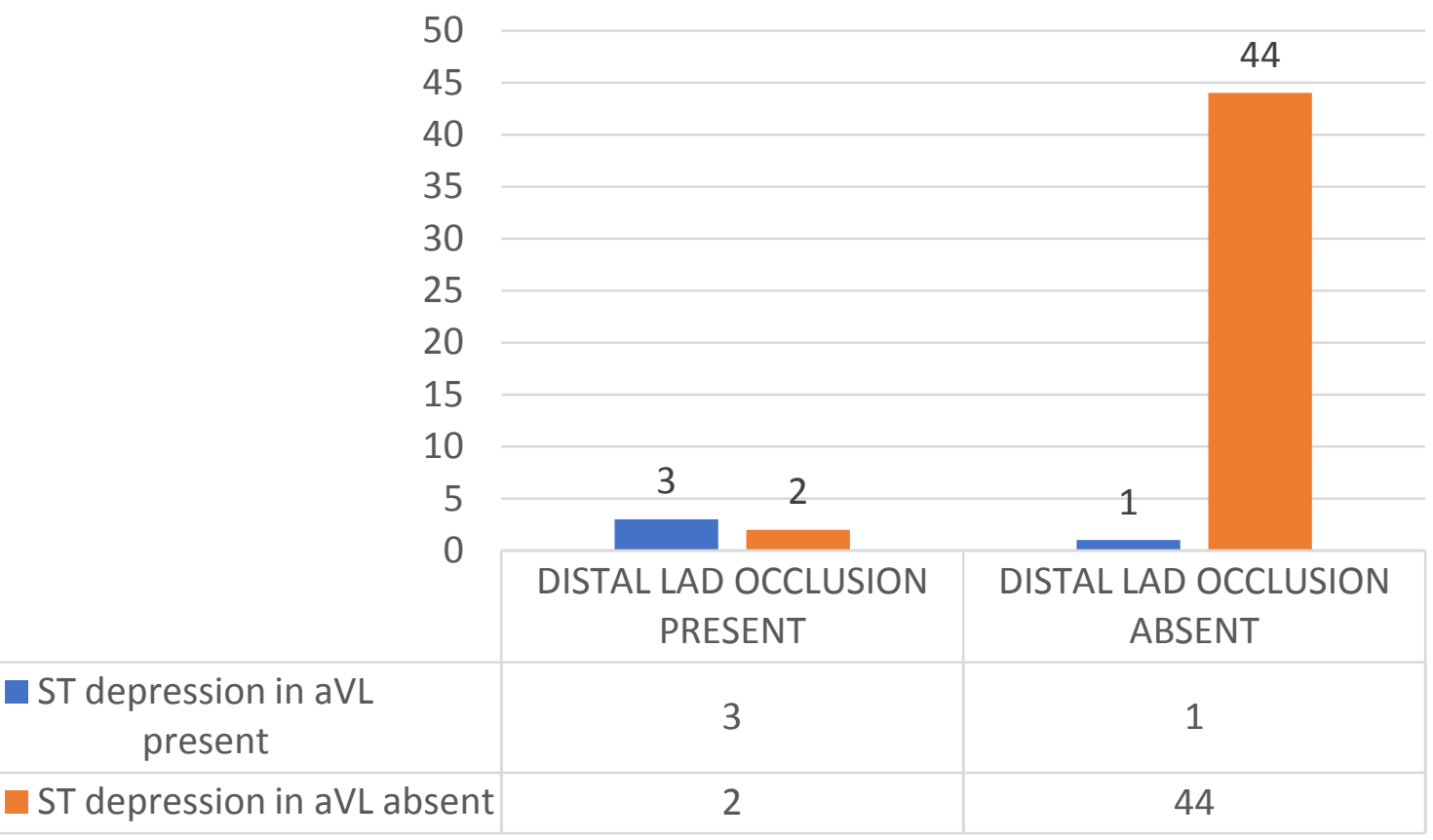

ST depression in aVL present

ST depression in aVL absent

\begin{tabular}{|c|c|c|c|c|c|c|}
\hline \multicolumn{7}{|c|}{$\begin{array}{l}\text { Comparison of various criteria to identify culprit ve } \\
\text { INFARCTION) }\end{array}$} \\
\hline \multirow[t]{2}{*}{ Parameters } & \multicolumn{2}{|c|}{ Present Study } & \multicolumn{2}{|c|}{ Vasudevan et al. ${ }^{[7]}$} & \multicolumn{2}{|c|}{ Engelen et $a ._{.}^{[5]}$} \\
\hline & Sensitivity & Specificity & Sensitivity & Specificity & Sensitivity & Specificity \\
\hline \multicolumn{7}{|l|}{ PROXIMAL LAD } \\
\hline ST elevation $V_{1}>2.5 \mathrm{~mm}$ & $59 \%$ & $89.2 \%$ & $71 \%$ & $66 \%$ & $12 \%$ & $100 \%$ \\
\hline ST elevation aVR & $63.6 \%$ & $92.8 \%$ & $50 \%$ & $100 \%$ & $43 \%$ & $95 \%$ \\
\hline Complete RBBB & $54.5 \%$ & $100 \%$ & - & - & - & \\
\hline $\begin{array}{l}\text { Inferior lead ST depression } \\
>1 \mathrm{~mm}\end{array}$ & $81.8 \%$ & $89.2 \%$ & $90 \%$ & $85 \%$ & $49 \%$ & $85 \%$ \\
\hline \multicolumn{7}{|l|}{ DISTAL LAD } \\
\hline $\begin{array}{l}\text { Absence of inferior leads } \\
\text { ST depression }\end{array}$ & $80 \%$ & $93.3 \%$ & $82 \%$ & $89 \%$ & $50 \%$ & $86 \%$ \\
\hline ST depression in aVL & $60 \%$ & $97.7 \%$ & $10 \%$ & $100 \%$ & $22 \%$ & $95 \%$ \\
\hline
\end{tabular}

\begin{tabular}{|c|c|c|c|c|c|c|}
\hline \multicolumn{7}{|c|}{ Comparison of Sensitivity and Specificity of our study with other similar studies } \\
\hline \multirow[t]{2}{*}{ ECG Parameters } & \multicolumn{2}{|c|}{ Present Study } & \multicolumn{2}{|c|}{ Nair and Glancy et al. $^{[10]}$} & \multicolumn{2}{|c|}{ Markandeya Rao et al..$^{[1]}$} \\
\hline & Sensitivity & Specificity & Sensitivity & Specificity & Sensitivity & Specificity \\
\hline \multicolumn{7}{|l|}{ RCA occlusion } \\
\hline ST depression aVL> LI & $76.9 \%$ & $94.5 \%$ & $100 \%$ & $60 \%$ & $82 \%$ & $73 \%$ \\
\hline $\begin{array}{l}\text { ST elevation }>1 \mathrm{~mm} \text {, } \\
\text { Upright } \mathrm{T} \text { in } \mathrm{V} 4 \mathrm{R}\end{array}$ & $55.5 \%$ & $95.1 \%$ & $86 \%$ & $100 \%$ & $71 \%$ & $66 \%$ \\
\hline \multicolumn{7}{|l|}{ LCx occlusion } \\
\hline ST elevation LII> LIII & $71.4 \%$ & $97.6 \%$ & $60 \%$ & $100 \%$ & $55 \%$ & $84 \%$ \\
\hline
\end{tabular}




\section{Discussion}

- Out of 35 patients with Anterior Wall MI, ECG criteria for proximal LAD occlusion with $100 \%$ specificity is RBBB. Most sensitive $(81.8 \%)$ finding for proximal LAD occlusion is ST depression $>1 \mathrm{~mm}$ in inferior leads with p-value $=0.001$ which is consistent with study done by Vasudevan et.al

- ST elevation in L II > L III remains the most sensitive (71.4\%) and most specific(97.6\%) with positive predictive value (PPV $=71.4 \%$, Negative predictive value $=95.4 \%$ with $\mathrm{p}$ value $<0.001$ for $\mathrm{LCX}$ occlusion which is consistent with Nair and Glancy et.al study

- Isoelectric ST segment in L II,L III, aVF is the most sensitive(80\%),ST depression in aVL has specificity of $97.7 \%$ in case of Distal LAD occlusion on angiogram which are consistent with studies done by Vasudevan et al. and Engelen et. al.

- Most specific (95.1\%)ECG criteria for proximal RCA occlusion is ST elevation > $1 \mathrm{~mm}$,upright $\mathrm{T}$ in V4R (sensitivity $=55.5 \%$, positive predictive value $=71.4 \%$, Negative predictive value $=90.6 \%, \mathrm{p}$ value $<0.001)$ and ST depression in aVL>L1 has sensitivity of $76.9 \%$,specificity $=94.5 \%$, $\mathrm{PPV}=83.3 \%, \mathrm{NPV}=92.1 \%$ ) for distal RCA occlusion which is consistent with study done by Nair and Glancy et. al

- $\quad$ ST elevation in L II=L III has sensitivity and specificity of $57.1 \%$ \& $95.3 \%$ respectively for LCX occlusion.

- ST elevation in aVR (sensitivity-63.6\%, specificity-92.8\%) and Q wave in aVL (sensitivity-68.1\%, specificity-92.8\%) for proximal LAD occlusion.

\section{Conclusion}

The admission ECG is valuable in locating, localising the culprit artery and also provide information about the extent of the myocardial injury.
The ECG changes predict the culprit vessel but cannot be a substitute for the angiogram which is considered to be the gold standard.

\section{Limitations}

Our study was conducted in a limited timeframe and population. A larger population from different continents and longer study will be needed to provide more accurate information regarding the appropriateness of ECG findings.

\section{Financial Support and Sponsorship: None Conflicts of Interest: None}

\section{References}

1. Markandeya RGKM, Ravindra KS, Nallamaddi $\mathrm{N}$. The Role of Ecg in Localizing The Culprit Vessel Occlusion in Acute ST Segment Elevation Myocardical Infarction with Angiographic Correlation. J Evid Based Med Healthc 2015; 2:8877-85.

2. Stefano S, Diego A, Christopher BG, Giorgio M, et al. Prognostic Value of the Admission Electrocardiogram in Acute Coronary Syndrome. JAMA 1999; 281:707-13.

3. Salunke KK, Khyalappa RJ. Role of electrocardiogram in identification of culprit vessel occlusion in acute ST elevation myocardial infarction in relation to coronary angiography. J Clin PrevCardiol 2017; 6:128-32.

4. Engelen DJ, Gorgels AP, Cheriex E C, et al. Value of the electrocardiogram in localizing the occlusion site in the left coronary artery in acute anterior anterior myocardial infarction. J Am Coll Cardiol; 34:389-395.

5. Engelen DJ, Gorgels AP, Cheriex E C, et al. Value of the electrocardiogram in localizing the occlusion site in the left coronary artery in acute anterior anterior myocardial infarction. J Am Coll Cardiol; 34:389-395. 
6. Birnbaum Y, Sclarovsky S, Mager A, Strasberg B, Rechavia E. ST segment depression in a VL: A sensitive marker for acute inferior myocardial infarction. Eur Heart J 1993;14:4-7.

7. Vasudevan K, Manjunath CN, Srinivas KH, Prabhavathi, Davidson D, Kumar S, et al. Electrocardiographic localization of the occlusion site in left anterior descending coronary artery in acute anterior myocardial infarction. Indian Heart J 2004;56:315-9.

8. Zimetbaum PJ, Krishnan S, Gold A, Carrozza JP 2nd, Josephson ME. Usefulness of ST-segment elevation in lead III exceeding that of lead II for identifying the location of the totally occluded coronary artery in inferior wall myocardial infarction. Am J Cardiol 1998;81:918-9.

9. World Health Organization. The World Health Report 2012: Reducing Risks, Promoting Healthy Life. Geneva: WHO; 2012.

10. Nair R, Glancy DL. ECG discrimination between right and left circumflex coronary arterial occlusion in patients with acute inferior myocardial infarction: Value of old criteria and use of lead aVR. Chest 2002;122:134-9. 